\title{
On the Aesthetic Education of Students Majoring in Information Technology
}

\author{
Ning Li ${ }^{*}$, Yanfang Fan, Zhi Jing \\ Computer School, Beijing Information Science and Technology University, Beijing, China \\ Email address: \\ ningli.ok@163.com (Ning Li), fyfhappy@bistu.edu.cn (Yanfang Fan),jz_hj@126.com (Zhi Jing) \\ ${ }^{*}$ Corresponding author
}

To cite this article:

Ning Li, Yanfang Fan, Zhi Jing. On the Aesthetic Education of Students Majoring in Information Technology. Higher Education Research. Vol. 6, No. 5, 2021, pp. 132-137. doi: 10.11648/j.her.20210605.16

Received: August 25, 2021; Accepted: September 16, 2021; Published: September 23, 2021

\begin{abstract}
Today, information technology has become an important factor of productivity to promote social development. It combines with all industries in the world, develops rapidly, and has a profound impact on human production and life. Aesthetic education plays a high role in China's higher education. For a long time, people have formed much understanding of the aesthetic education of engineering majors, while information technology, as a new engineering major intersecting with all industries, has more urgent, comprehensive and profound requirements for aesthetic education. As the cradle of information technology talents, how to cultivate talents leading the development of the times has become an important topic. This paper, starting from the problems faced by aesthetic education of colleges and universities and combined with the characteristics of information technology major, points out that the purpose of information technology major to carry out aesthetic education is to achieve harmony between man and nature and ensure that information technology benefits human society, aiming to let students develop aesthetic consciousness and aesthetic ability, shape perfect personality, and create beautiful things. The paper also discusses the connotation of aesthetic education of information technology major, pointing out that information technology major should realize the organic combination of aesthetic knowledge and professional accomplishment based on its training objectives, strengthen students' document writing ability, human-machine interface design ability and code design ability in line with aesthetic requirements, and cultivate talents good at communication and cooperation and meet the needs of the information age. Based on these ideas, this paper puts forward the assumption of offering the course of"Innovative Thinking and Aesthetic Cultivation".
\end{abstract}

Keywords: Aesthetic Education, Aesthetic Appreciation, Information Technology, Innovation

\section{Introduction}

In today's information society, information technology has become an important factor in the productive forces that promote social development. It develops rapidly and is integrated with all industries around the world, profoundly affecting the production and life of human beings. As the cradle of information technology talents, information technology major is facing an important issue of how to cultivate talents leading the development of the times.

China began to promote quality education around 2000. At the end of 2013, the third Plenary Session of the 18th CPC Central Committee clearly proposed the task of "improving aesthetic education teaching and enhancing students' aesthetic and humanistic qualities". In 2015, aesthetic education was included in the Education Law and the Higher Education Law. It is fortunate that we have realized the importance of aesthetic education and continued to promote its implementation in higher education.

Currently, there are many defects in the training of information technology talents. Although students learn a lot of technology in school, they cannot produce products that meet the needs of users. For example, many human-computer interfaces are confusing and daunting, many electronic products are crude, stupid in design and difficult to use, many IT practitioners are withdrawn and difficult to communicate, many articles are too cluttered to read, and much of the code lacks logic and is hard to be understood. After thinking deeply about these phenomena, we come to the conclusion: students majoring in information technology need to 
strengthen aesthetic education.

Many scholars have made in-depth discussions on the importance of aesthetic education to engineering students. Zhu Liyuan believes that aesthetic education could support the construction of "new engineering majors" in the following three dimensions: cultivating innovation ability urgently needed for the construction of "new engineering majors", remolding the dimension of technological beauty in technological development, and helping technology better evolve into life [1]. According to Wang Shixia and Liu Deqiang, incorporating aesthetic education into the teaching process of science and engineering majors, to let students feel the truth of nature and the beauty of laws contained in science and technology, can not only improve students' literacy and learning interest, and promote the cultivation of students' creative ability, but also can stimulate students' sense of responsibility and sense of mission, shape students' healthy personality, sublimate their scientific temperament and mental state [2]. Yang Jie views that, in order to avoid the alienation of science and technology of today, it is necessary to make the inventors, converts and applicators of science and technology become fully developed people, and it is of equal practical significance to eliminate scientific blindness and aesthetic blindness [3]. Mei Yunbin and Zeng Jiamin analyzed the problems existing in aesthetic education of science and engineering universities, and explored the practical path for the development of aesthetic education of science and engineering universities from five dimensions, namely, thought, curriculum, environment, practice and network [4].

Although many scholars recognize the importance of aesthetic education to engineering students, there are few studies on aesthetic education from the perspective of information technology. As a new engineering subject intersecting with all industries, information technology has more urgent, comprehensive and profound requirements for aesthetic education. This paper attempts to analyze the necessity of aesthetic education from the perspective of the demand for information technology talents cultivation, and puts forward the idea of how to carry out aesthetic education in information technology major on the basis of the demand.

\section{The Aesthetic Requirement of Information Technology Talents}

The definition of "beauty" has always been the focus in the field of aesthetics, which forms a variety of schools. Ci Hai (Philosophy volume $\cdot$ Aesthetics $\cdot$ Principles) defines beauty as: pleasing and adoring images discovered and created in nature, society, material and spirit. It is the unity of subject and object, objectivity and sociality, law and purpose, and sensibility and rationality [5]. In other words, beauty embodies the essence of the harmony of all things.

Information technology is a double-edged sword. Its healthy development will help to create a better society, to achieve a high degree of harmony between man and nature, and among people; but if it deviates from this trajectory, it could lead us to disaster. For example, today's big data brings great convenience to our life, but also brings great risks of privacy leakage. Li Zehou said that the advancing social purpose has become the form of object's law conformity [6]. Therefore, the fundamental purpose for information technology major providing aesthetic education is to let students have the vision to identify the beauty of harmony and to ensure that information technology can truly benefit mankind.

The goal of aesthetic education of information technology major is not only to let students know what is beauty, but also to teach students how to create a beautiful personality and how to create beautiful things. This is closely related to the characteristics of information technology talents.

First, students majoring in information technology need to have aesthetic ability, so that they are able to develop humanized IT products.

Looking back into the past, excellent information technology products must be rich in humanity, and can shorten the distance between man and machine, which is the embodiment of harmony between man and nature. If what artists pursue is the beauty of art, then what engineers pursue is the beauty of technology, and these two kinds of beauty present a high degree of harmony and unity in IT products.

The classic example is the design of Apple's series of consumer electronics products. Apple in the era of Steve Jobs perfectly realized the combination of technology and art, and its products pay attention to user's feelings and experience, fashion and taste. From personal computers, to iMac, iPod, iPhone, iPad and other popular electronic products, they have profoundly changed the way of human communication, entertainment and even life, and also given the film, music, telecommunications, retail, publishing and design industries a new look [7].

Such a success depends on Jobs, both an engineer and an artist. Rodin once said: Beauty is everywhere. For our eyes, there is not a lack of beauty, but a lack of discovery [8]. Our aesthetic education should make students majoring in information technology good at discovering beauty from life, and pursuing beauty, so as to cultivate a number of talents like Jobs.

IT products are different from other products, and there are both tangible ones and more intangible ones. In the past, the object of industrial design is mainly tangible products, but many IT products exist in the form of software, and for some we even cannot feel their physical existence, such as virtual reality works. On the other hand, IT products, in order to be accepted by the public, need to achieve multi-dimensional harmony in time, space, psychology and culture, so as to improve the quality of life and spiritual enjoyment of human beings. Therefore, the information technology professional has higher requirements in aesthetic appreciation. Only subject knowledge and skills are unable to meet the requirements, and forward-looking, compound talents are needed.

Second, students majoring in information technology need 
to arouse their innovation ability through aesthetic appreciation.

Innovation is the driving force of the development of information technology, and innovation is the core of art. The essence of technological and artistic innovation is to discover and create the beauty of harmony, and this process is called innovation. We need to teach students to spot incongruity, so as to stimulate their imagination and creativity. Qian Xuesen once said: from the perspective of thinking science, scientific work always begins with conjecture, and then turns to scientific proof. In other words, scientific work originates from imaginal thinking and ends in logical thinking, while imaginal thinking comes from aesthetic art. Only by cultivating the aesthetic accomplishment of scientific and technological workers can more creative results be achieved [9]. This may be the reason why there are many great scientists who are also artists, such as Einstein, Li Siguang, Qian Xuesen, all of them were proficient in music. Classical aesthetic theories discovered the golden ratio in composition, the relationship between music and sequence, etc., and gradually formed the design principles of technical aesthetics. CAI Yuanpei said that there is no school curriculum that has nothing to do with aesthetic education. Taking Math as an example, it seems to be boring, but the aesthetic proportion and rhythm are all the relationship of numbers [10].

Excellent IT products should achieve the unity of functional beauty, technical beauty, formal beauty and artistic beauty $[11,12]$. In fact, any beautiful thing presents different forms of internal or external beauty, such as the texture beauty of utensils, the convenience beauty of interface, the logic beauty of programs, the rhetoric beauty of expression and so on. Yang Jie said that, it is precisely because of this transcendent nature of aesthetic ideal that it has gained the status of "lighthouse" in human aesthetic practice, and guides people to create aesthetic objects with purpose. This is also the existential significance of aesthetic ideals, that is, creativity [3].

A friend of the author once talked about their photo studio that, retouching the photos was a big challenge after taking wedding photos for customers, because the bride and groom have different understandings of beauty, and it is difficult for the retouched pictures to satisfy both sides. The retoucher often fretted about this and spent a lot of time on this. $\mathrm{He}$ asked us whether there is a way for a computer to automatically create the most beautiful wedding photos without changing key facial features. This is a subject of innovation guided by aesthetic principles, and today's AI technology is likely to make this happen.

From this we can see that innovation also brings broad market space for IT products. As Mr. Jobs said, consumers may not even know what their next consumer product is, but Apple can provide them with consumer electronics that make them fondle admiringly. In his view, if there is no markets, then create a market, and if no demand, create demand, and scientific and technological innovation has this potential function [6].

Furthermore, information technology talents need a sound personality, both in EQ and IQ.

Information technology intersects with almost every other discipline, breaking down industry boundaries. The talents who can control information technology should have rich knowledge, broad vision, humanistic sensations, rational thinking, inclusive spirit, leadership temperament and integrative competence. From the perspective of aesthetic education, it means that they are necessary to have a perfect personality. Schiller pointed out that, there is no other way to make an emotional person into a rational person, except to make him an aesthetic person first [13]. CAI Yuanpei also said that aesthetic education can provide the greatest help for self-cultivation [14].

There is a misunderstanding among students of information technology, that is to pursue advancement in technology one-sided, but do not pay attention to the improvement of personality. "Science geeks" give people the impression that they are often a group of eccentric people who are undisciplined, inarticulate, unsophisticated, and unromantic, far from what we require for information technology talents today. The aesthetic education of information technology major should pay attention to change this stereotypical image of "science geeks", cultivate students' interpersonal communication and collaboration ability, and turn them from "inconspicuous ones" to "great talents". Nowadays, no important information technology achievement can be made behind closed doors, and it even requires global cooperation, mutual respect, mutual understanding and common development, and thus IT talents with both EQ and IQ are more needed.

Information technology of today changes with each passing day and the competition is fierce, bringing great pressure to IT practitioners. As far as we know, information technology-related majors, especially computer science major, had the highest numbers of people suffering from depression or psychological disorders compared to other majors, and in any organization or event, this group of people provides the fewest activists. With aesthetic education, we can delight the students with a sense of beauty, to help them develop a positive, relaxed, optimistic state of mind, expel "anxiety", and become a healthy practitioner. Just as Hegel said, aesthetic activity is a kind of soul liberation, a process of getting rid of all repression and restrictions, with liberating nature [15].

\section{Recommendation on Aesthetic Education of Information Technology Major}

At present, aesthetic education in colleges and universities is spreading rapidly, but the proportion of humanities and aesthetic education courses is still low. Besides, the contents of these courses are mostly directly copied from the courses of art majors or combined with moral education [16] and few are deeply integrated with professional contents, indicating that aesthetic education in colleges and universities is out of 
line with the training objectives of majors.

The authors believe that aesthetic education of information technology major should integrate aesthetic common sense and professional accomplishment organically.

The aesthetic education of information technology major should focus on the aesthetic elements and principles related to information technology, so as to equip students with the necessary aesthetic knowledge. In this regard, courses such as introduction to art, art/music appreciation, and engineering aesthetics can be taught selectively. In addition, practical courses such as photography, art and calligraphy can be added as supplement, because it is difficult for students to experience the beauty without practice. Students majoring in information technology can understand the essence of beauty more deeply by combining information science. From our point of view, the sense of beauty is also a kind of information (or aesthetic information) in essence, which is encoded in aesthetic objects, such as music, painting and architecture, bringing people pleasure. From this point of view, music, painting and architecture are all carriers of aesthetic information. The nature of information is exactly the same, which is the meaningful content extracted from the carrier of information (such as sound, image, text, etc.). Today, more and more information carriers are presented in the form of digital, and we can perceive the colorful information world from the rhythm of digital. The transmission of aesthetic information also has its internal laws, such as: elegance, symmetry, simplicity, harmony, unity, and so on. Can we prompt the students to think about using the concept of entropy to calculate the amount of information in beauty?

For students majoring in information technology, their future output could be as diverse as a piece of equipment, a circuit, a set of software or a thesis. The beauty of creation is contained in each of these works. In this respect, we should pay attention to let students understand the nature and characteristics of innovative thinking, types and forms of innovation, so as to equip them with basic innovative consciousness and innovative thinking. According to the foregoing aesthetic requirements of information technology major, we should focus on strengthening students' ability in three aspects: 1) Ability to write and polish documents. It seems not hard, but most people struggle to meet it. The writing of documents and papers is the basic skill of college students, and they should be of beautiful layout, smooth expression, rigorous structure and elegant rhetoric. 2) Ability to design human-machine interface. Focusing on information products, we need to explain the elements and rules of human-machine interface design with examples, and highlight the people-oriented and user-centered design concept, so as to enable students to design refreshing man-machine interface with perfect functions and good user experience. 3) Ability to design code. We need to discuss the aesthetic elements of software design, and with the help of standard, concise, smooth, and easy to understand code design style, to make a program, no matter how complex it is, being quickly understood, easily maintained, and freely extended.

In order to shape the personality of students majoring in information technology, we can, together with students, analyze the personality characteristics of leaders in the information technology industry. For example, we can learn the life experiences of scientists and entrepreneurs like Ciyungui, Wang Xuan and Ren Zhengfei, to discover the beauty of fearlessness, fortitude, pragmatism and struggle in their characters, and learn the beauty of the inheritance, collaboration and innovation of the Beidou navigation research and development group. Next, we need to teach our students the beauty of social etiquettes in dealing with people. Taking open source software as the example, we should let students know how we collaborate in the open source community, how we handle disputes, and how we respect others. We also should let them know how to ask for help without being boring, how to help others by teaching them to help themselves. and how to interact with people through email, Wechat, and social networks, so as to become a person respected and welcomed by others.

Beijing Information Science and Technology University is characterized by information technology and aims to train high-quality applied talents. In addition to the related public electives, we offer a course for students majoring in information technology, namely "Innovative Thinking and Aesthetic Cultivation", which covers all of the above points. This course contains 16 credit hours, is an elective course for senior college students and postgraduate students. The goal of the course is to cultivate students' innovative consciousness and aesthetic accomplishment while combining the characteristics of information industry, and form the innovative design ability in line with aesthetic requirements. The teaching contents include:

(1) Innovative thinking in information technology. Discussing the importance of innovation in information technology development and research activities, the nature and characteristics of innovative thinking, types and forms of innovation, so as to equip students with basic innovative consciousness and innovative thinking.

(2) Aesthetic accomplishment of IT practitioners. Discussing what aesthetic qualities, aesthetic elements and basic principles the practitioners of information technology should have, so as to improve the aesthetic consciousness of students.

(3) The beauty of typesetting design. Taking examples of common publications and literary forms, explaining the principles, rules and methods of typesetting from the aspects of software technology, typesetting elements, layout composition, text arrangement, picture placement, and color application, to enable students to use common document typesetting tools to design a scientific, rigorous and beautiful typesetting work.

(4) The beauty of interface design. Focusing on information products, explaining the elements and rules of human-machine interface design with examples, and highlighting the people-oriented and user-centered design concept, to enable students to design creative and aesthetic human-machine interface with perfect functions and good user experience. 
(5) The beauty of code design. Discussing the aesthetic elements in software design, and making the code being quickly understood, easily maintained and freely expanded with the help of standard, refined, harmonious and smooth code design style, to enable students to be a popular and respected software engineer in the future.

(6) The beauty of social etiquettes. Discussing the social etiquette that should be paid attention to when using modern information tools (such as E-mail, Wechat) to communicate and cooperate, strengthening students' cultural accomplishment and improving their communication skills.

(7) Computer art. Through lectures and observation, studying the new art forms generated under the combination of information technology and aesthetics and the impact on aesthetic concepts.

As it is a newly opened course, we will continue to practice and improve our aesthetic education concept and teaching level. We have realized that the construction of aesthetic education involves curriculum objectives, teaching staff, curriculum content, and teaching methods, thus it is by no means easy to be done well immediately, and we will be firm in this idea and continue to make improvement.

\section{Conclusion}

In April 2019, the Ministry of Education issued the Opinions on Strengthening Aesthetic Education in Colleges and Universities in the New Era, pointing out that beauty is an important source of moral purity and spiritual enrichment. Aesthetic education in schools is the work of nurturing the root and soul of a person. It is an important task of higher education at present and in the future to improve students' aesthetic and humanistic qualities and to strengthen and improve aesthetic education in an all-round way. In 2020, the Ministry of Education established the first National College Aesthetic Education Teaching Guiding Committee, marking the work of college aesthetic education has entered a new stage of development.

Beauty is a bridge between science and art, and a beacon for social progress. The purpose of aesthetic education is to cultivate students' ability to discover, love and create beauty. Its fundamental purpose is to use beauty to identify good and evil, so as to ensure that science and technology really benefit human society. To carry out aesthetic education of information technology major is conducive to improving students' aesthetic level so as to design humanized products. Besides, students majoring in information technology need to wake up their innovative ability and improve their personality with aesthetic appreciation, so as to lead the development of IT technology.

For students majoring in information technology, general aesthetic education is often not enough. According to the professional characteristics of information technology and combined with the orientation and goal of talent training, we should strengthen the cultivation of aesthetic ability in the following aspects: the teaching of aesthetic elements and principles related to information technology, grasping the essence of beauty based on information science, shaping a perfect personality, and cultivating information technology talents who adapt to the times and are welcomed by the society; combined with the needs of the major, cultivating students' aesthetic consciousness and innovation ability in document writing, human-machine interface design, and code writing. In addition, the research and discussion on the new art form produced by the combination of information technology and aesthetics and its impact on the aesthetic concept will also help to give birth to the information technology products integrating technical beauty and artistic beauty in the future.

Beijing Information Science and Technology University has carried out preliminary exploration in IT aesthetic education, and looks forward to having more experience and achievements to share with you in the future. Together with colleagues, we are making efforts to build a diversified, high quality and modern socialist aesthetic education system with Chinese characteristics.

\section{Acknowledgements}

Discipline Development and Graduate Education Project of Beijing Information Science \& Technology University: Computer Science and Technology - Artificial intelligence and independent innovation talent training support platform.

\section{References}

[1] Zhu Liyuan, Xiong Teng. On the Role of Aesthetic Education in the Construction of"New Engineering Majors" [J]. Journal of South China University of Technology: Social Science Edition, 2018, 20 (06): 108-115.

[2] Wang Shixia, Liu Deqiang. Study on the Value Function of Aesthetic Education in the Teaching of Science and Engineering Colleges [J]. Creative Education Studies, 2019, 7 (5): 5 .

[3] Yang Jie. Research on the Relationship between Scientific Aesthetic Education and Quality Education for Science and Engineering College Students [J]. Higher Education Exploration, 2007, 000 (005): 22-27.

[4] Mei Yunbin, Zeng Jiamin. Value Implication and Practice Path of Aesthetic Education in Science and Engineering Universities [J]. Journal of Wuhan Polytechnic, 2020, 019 (001): 98-103.

[5] Great Cihai Editorial Board. Ci Hai (Philosophy volume Aesthetics Principles) [M]. Shanghai Lexicographical Publishing House. 2015.

[6] Li zehou. The Path of Beauty [M]. Tianjin: Tianjin Academy of Social Sciences Press.

[7] Bao Jianqiang. The Scientific and Technological Value Orientation and Spiritual Legacy of Steve Jobs, Founder of Apple [J]. Journal of Zhejiang University of Technology: Social Science, 2014 (13): 387.

[8] Rodin. Rodin: L' Art [M]. People's Fine Arts Publishing House, 1987. 
[9] Qian Xuemin. On Qian Xuesen's Scientific View and Methodology [J]. Science and Technology Literature, 1996 (7): $1-9$.

[10] Cai Yuanpei. Collections of Aesthetic Education of CAI Yuanpei [M]. Changsha: Hunan Education Publishing House, 1989.

[11] Luo Junjun. Aesthetic Application [M]. Beijing: Social Sciences Academic Press, 1998.

[12] Xu Hengchun. Aesthetics of Practical Technology -- Product Aesthetic Design [M]. Tianjin Science and Technology Press, 1995.
[13] Schiller. Aesthetic Letters [M]. Translated by Xu Hengchun. Beijing: China Federation of Literary and Art Circles Publishing House, 1984.

[14] Cai Yuanpei. Complete Works of CAI Yuanpei (Volume 3) [M]. Beijing: Zhonghua Book Company, 1988.

[15] Hegel. Aesthetics (Volume 1) [M]. Beijing: The Commercial Press, 1979.

[16] She Xing, Zhang Le. The Present Situation and Reform of Aesthetic Education in Engineering Colleges [J]. Journal of Anhui University of Technology (Social Sciences), 2012 (02): $142+144$. 